\title{
O LIVRO DIDÁtico E AS ATIVIDADES DE LEITURA DO GÊNERO DISCURSIVO ENTREVISTA
}

Cristiane Malinoski Pianaro Angelo*

Loremi Loregian PenKaL**

\section{RESUMO}

Fundamentado nos pressupostos bakhtinianos, este artigo busca analisar as atividades de leitura do gênero entrevista apresentadas no livro didático Português: uma proposta para o letramento, de Magda Soares, publicado em 2002. Os resultados da análise apontam que as propostas do livro podem suscitar importantes reflexões nas aulas de Língua Portuguesa, pois nele há questões que despertam no aluno a réplica ativa. Além delas, em sala de aula, há outras questões que podem ser apresentadas pelo professor como, por exemplo, as noções de interlocutor e autoria; a finalidade social da entrevista; os vínculos entre a seleção das marcas linguísticas e as condições de produção.

Palavras-chave: atividades de leitura, gênero entrevista, livro didático.

\section{CONSIDERAÇÕES INICIAIS}

O presente artigo, vinculado ao Grupo de Pesquisa Interação e Ensino (Unicentro/CNPq), trata das atividades de leitura do gênero entrevista apresentadas no livro didático Português: uma proposta para o letramento, livro 7 ( $8^{\circ}$ ano do Ensino Fundamental), de Magda Soares. Tem-se por objetivos analisar e discutir ${ }^{1}$ algumas atividades propostas, bem como fomentar e sugerir novas leituras e proposições às questões trabalhadas pela autora.

* Doutoranda em Letras pela Universidade Estadual de Maringá; professora do Departamento de Letras da Universidade Estadual do Centro-Oeste (Unicentro), Campus de Irati.

E-mail: malinoskicristiane@uol.com.br

** Professora do Departamento de Letras da Universidade Estadual do Centro-Oeste (Unicentro), Campus de Irati.

E-mail: loremi.loregian@gmail.com 
Para tanto, o texto está organizado da seguinte forma: primeiro, recuperam-se alguns conceitos fundamentais de Bakhtin e o Círculo (1999; 2003), como linguagem, dialogismo, enunciado e gêneros do discurso. Em seguida, discutem-se as atividades propostas no livro didático, em virtude de ter sido selecionado pelo Guia de Livros Didáticos - PNLD/2011 (BRASIL, 2010), um programa que tem como objetivo prover as escolas da rede municipal, da estadual e da federal com obras didáticas de qualidade.

\section{REVISÃO DA LITERATURA}

\subsection{Linguagem e dialogismo}

As proposições bakhtinianas concernentes aos fenômenos envolvidos nos usos da língua são as que fundamentam este estudo. Isso significa que estamos propondo uma abordagem dialógica do estudo da lingua(gem) no contexto escolar, isto é, uma abordagem que leva em consideração os falantes e seus atos e o contexto social.

A noção de dialogismo é o conceito-chave nos fundamentos filosóficos de Mikhail Bakhtin e o Círculo. Nessa perspectiva, todo dizer consiste em uma réplica a outros dizeres. Para o filósofo, "toda enunciação [enunciado], mesmo na forma imobilizada da escrita, é uma resposta a alguma coisa e é construída como tal. Não passa de um elo da cadeia dos atos de fala. Toda inscrição prolonga aquelas que a precederam, trava uma polêmica com elas, conta com as reações ativas da compreensão, antecipa-as" (BAKHTIN e Volochinov, 1999, p. 98).

As produções acadêmicas, como o artigo científico, por exemplo, constituem um diálogo, pois são uma reação a ditos anteriores e, uma vez realizadas, serão alicerces para outras reações-resposta. Elas surgem em razão de trabalhos anteriores, refletindo sentidos, visões de mundo e exercendo influência sobre os trabalhos posteriores, visto que são base para estudos, apreciações críticas, comentários e resenhas. Dessa forma, assim como a comunicação face a face, os autores afirmam que "o discurso escrito é de certa maneira parte integrante de uma discussão ideológica em grande escala: ele responde a alguma coisa, refuta, confirma, antecipa as respostas e objeções potenciais, procura apoio, etc." (p. 123); enfim, o discurso está em constante diálogo com outros discursos. 
Bakhtin reage ao tratamento da língua como um todo isolado que se sustenta em si mesmo (o objetivismo abstrato), criticando-o e defendendo um estudo do fenômeno linguístico em sua totalidade, ou seja, no interior das relações sociais, pois a "interação verbal constitui assim a realidade fundamental da língua” (BAKhtin e Volochinov, 1999, p. 123). Trata-se, então, de estudar a língua como discurso, em sua integridade concreta e viva. A língua, materializada como discurso, realiza-se na forma de enunciados - sendo o enunciando a unidade real e concreta da comunicação discursiva - que, por sua vez, não se esgotam nos limites da dimensão linguística, mas sempre se encontram vinculados às condições da situação de interação social (por isso são únicos e irrepetíveis na comunicação discursiva) e a outros enunciados (porque são sempre respostas a outros enunciados).

Rodrigues (2005) observa que o enunciado, na perspectiva bakhtiniana, possui um "horizonte extraverbal" que pode ser analisado em três elementos essenciais. O primeiro deles é o horizonte espacial e temporal, que consiste em compreender o "onde" e o "quando" do enunciado, o contexto de interação; o segundo - o horizonte temático (objeto e conteúdo temático do enunciado) - compreende o que se fala e a finalidade do enunciado; e o terceiro refere-se ao horizonte axiológico, ou seja, à atitude dos interlocutores em relação ao objeto do enunciado, aos outros enunciados e aos interlocutores.

A partir da compreensão de que os elementos extraverbais são constitutivos do enunciado, pode-se conceber a lingua(gem) como fenômeno social e interacional, o que significa também afirmar que ela está sempre atrelada aos aspectos ideológicos.

Na realidade, não são palavras o que pronunciamos ou escutamos, mas verdades ou mentiras, coisas boas ou más, importantes ou triviais, agradáveis ou desagradáveis etc. A palavra está sempre carregada de um conteúdo ou de um sentido ideológico ou vivencial. (BAKHTin e Volochinov, 1999, p. 95; grifos do autor)

As formas de interação verbal acham-se muito estreitamente vinculadas às condições de uma situação social dada e reagem de maneira muito sensível a todas as flutuações da atmosfera social. (BAKHTIN e Volochinov, 1999, p. 42) 
Pensando a linguagem em todo o seu potencial social, interacional e ideológico, Bakhtin e Volochinov argumentam que ela precisa ser entendida e explicada a partir dos vínculos com as condições concretas em que se realiza; portanto, levando em conta também os sujeitos participantes da dinâmica interlocutiva e o meio extraverbal. Segundo os autores, "toda palavra comporta duas faces. Ela é determinada tanto pelo fato de que procede de alguém, como pelo fato de que se dirige para alguém. Ela constitui justamente o produto da interação do locutor e do ouvinte" (p. 113).

A palavra é socialmente dirigida. Assim, a interação não consiste em uma mera troca de turnos de uma interlocução, ela precisa ser compreendida como fator constitutivo da linguagem, que devolve ao interlocutor a condição de participante ativo da atividade comunicativa.

Na seção a seguir, vamos abordar, de modo geral, as concepções de leitura, tentando mostrar por que adotamos a posição responsiva ativa na análise aqui empreendida.

\subsection{A Leitura Na PERSPeCtiva BaKhtiniana De Linguagem: a Posição RESPONSIVA ATIVA}

Ao assumirmos as proposições bakhtinianas como princípios orientadores para o modo de se entender as práticas de leitura, estamos revisitando as diversas concepções tradicionais de leitura, questionando-as e buscando problematizar outros aspectos desconsiderados pelos estudiosos que propagam essas concepções.

Questionamos, assim, o modelo estruturalista - que corresponde à concepção de que ler é uma atividade de decodificação ou extração evidenciando o texto como o elemento principal da leitura, pois nele está inscrito o sentido, bastando ao leitor reconhecê-lo e reproduzi-lo, a partir de um minucioso trabalho de esquadrinhamento do material linguístico.

De acordo com Bakhtin e Volochinov (1999),

qualquer tipo genuíno de compreensão deve ser ativo, deve conter já o germe de uma resposta. [...] Compreender a enunciação de outrem significa orientar-se em relação a ela, encontrar o seu lugar adequado no contexto correspondente. A cada palavra da enunciação que estamos em processo de compreender, fazemos corresponder uma 
série de palavras nossas, formando uma réplica. (p. 131-132; grifos nossos)

A tarefa de decodificação ou extração - tal como propõe a orientação estruturalista - limita as condições de resposta, visto que lhe cabe apenas o papel de descobridor dos significados do texto, reservando-lhe um papel passivo. As noções bakhtinianas, pelo contrário, "acendem" o leitor, ao dar-lhe possibilidades de se constituir como participante ativo da atividade leitora.

$\mathrm{Na}$ atividade reprodutiva, não há também aquilo que Bakhtin e Volochinov denominam de "acento apreciativo":

Toda enunciação compreende antes de mais nada uma orientação apreciativa. É por isso que, na enunciação viva, cada elemento contém ao mesmo tempo um sentido e uma apreciação. Apenas os elementos abstratos considerados no sistema da língua e não na estrutura da enunciação se apresentam destituídos de qualquer valor apreciativo. (p. 135)

Se "a palavra está presente em todos os atos de compreensão e interpretação" (p. 38) e se sem acento apreciativo não há palavra, podemos considerar a leitura também como uma atividade apreciativa, o que reafirma a sua natureza interlocutiva. Nesse sentido, ler é emitir um julgamento de valor, é dialogar com a palavra, aceitando-a (o que não significa "reproduzi-la", mas perceber que há um processo de tomada de atitude em favor do locutor), rejeitando-a, questionando-a.

Questionamos, também, o modelo psicolinguístico de leitura que desloca as atenções para o papel do leitor no processamento do texto, considerando a leitura como um processo ativo de construção mental. Considera-se que o sentido é acionado pelos conceitos baseados nas experiências vivenciadas pelo leitor, anteriores ao seu contato com o texto e envolve múltiplas fontes de conhecimentos: linguísticos, textuais e de mundo.

Esse modelo teórico apresenta importantes contribuições para se entender o que acontece cognitivamente no momento da leitura, com base nesta indagação: "O que acontece quando lemos?". No entanto, o modelo muitas vezes reduz a leitura a um jogo de adivinhações. Para Bakhtin e Volochinov (1999, p. 132), “a significação não está na pala- 
vra nem na alma do falante, assim como não está na alma do interlocutor. Ela é o efeito da interação do locutor e do receptor [...]". Como a significação é construída no processo de interação, não há um polo (texto, leitor, autor) mais importante; é exatamente o traço de união que possibilita a significação.

Assim, tanto o modelo estruturalista como o psicolinguístico desconsideram alguns aspectos fundamentais das formulações bakhtinianas: os aspectos sociais e ideológicos que também estão envolvidos na compreensão responsiva ativa, uma vez que "a língua, no seu uso prático, é inseparável de seu conteúdo ideológico ou relativo à vida" (p. 96). Nessa perspectiva, ao interagir com o texto, o leitor precisa estar atento às visões de mundo veiculadas no dizer e, para isso, torna-se fundamental analisar determinadas condições extralinguísticas: o momento histórico-social em que se dá a produção, a posição social do autor, a finalidade sociodiscursiva do dizer - noções que só podem ser analisadas se o texto for trabalhado na perspectiva do enunciado, isto é, à luz das noções de gênero, problematizadas por Bakhtin (2003).

\subsection{GÊNERos Discursivos}

No cerne da concepção de linguagem e dialogismo bakhtinianos, as noções de gêneros do discurso ${ }^{2}$ precisam ser reconhecidas e problematizadas.

Assim, ao construir o enunciado, o locutor/produtor não pode fazê-lo de um modo aleatório, sem qualquer obediência a regras sociais; ele precisa organizar sua fala a partir de "tipos relativamente estáveis de enunciados, os quais denominamos gêneros do discurso", segundo Bakhtin (2003, p. 262), caso contrário, a interação torna-se impossível.

Rodrigues (2005), ao analisar os conceitos de gêneros em Bakhtin, observa que a definição de gênero como tipo de enunciado refere-se a uma "tipificação social dos enunciados que apresentam certos traços (regularidades) comuns, que se constituíram historicamente nas atividades humanas, em uma situação de interação relativamente estável, e que é reconhecida pelos falantes" (2005, p. 164). Nesse sentido, a noção de gênero bakhtiniana deve ser observada não quanto às propriedades formais, mas em sua relação com o contexto 
interacional, o que nos permite atribuir-lhe um caráter social, discursivo e dialógico.

Os gêneros discursivos apresentam estas três características essenciais que estão interligadas:

i) O conteúdo temático, isto é, o objeto e a finalidade discursivos, o que é dizível por meio do gênero;

ii) A construção composicional, ou seja, os aspectos estruturais compartilhados pelos textos pertencentes aos gêneros;

iii) $\mathrm{O}$ estilo representado pelos traços lexicais e gramaticais da língua e especificidades do autor (Bakhtin, 2003).

A variedade de gêneros do discurso é imensa, pois a variedade da ação humana, de sujeitos, de contextos sociais e ideológicos é infindável, e cada campo dessa ação admite um repertório de gêneros do discurso que se modifica com a ampliação e pela diversidade das atividades humanas. Em virtude disso, Bakhtin (2003) chama a atenção para as diferenças (ideológicas) existentes entre gêneros discursivos primários (simples) e secundários (complexos). Alguns gêneros secundários - o artigo científico, a resenha, a tese científica - surgem nas esferas de interação social mais complexas e organizadas, no âmbito de ideologias mais formalizadas, como a científica, a jurídica, a artística. Já os gêneros primários - como o relato familiar, a conversa telefônica entre amigos - constituem-se em contextos de comunicação vinculados a esferas sociais cotidianas, no cerne de ideologias menos formalizadas.

Logo, os gêneros primários são aqueles aos quais o aluno tem acesso em seu cotidiano e que os utiliza em situações corriqueiras e familiares, ao passo que aos gêneros secundários ele tem menos acesso e vai necessitar do apoio do professor para que possa conhecê-los e dominá-los e, desse modo, torne-se um sujeito mais crítico e atuante na sociedade em que vive.

É importante assinalar que Bakhtin (2003), ao realizar essa diferenciação, não pretende dividir os enunciados em dois grupos absolutamente estáticos e isolados entre si, pois, dessa forma, estaria negando a complexidade social, dialógica e ideológica da linguagem. Ele afirma que os gêneros secundários, no processo de sua constituição, absorvem e reelaboram diversos gêneros primários, como acontece com o romance que incorpora e reelabora gêneros primários como o diálogo cotidiano. 
Ressalte-se ainda que, como modos de dizer, os gêneros organizam e regulam a produção dos enunciados, o que torna possível a interação entre os sujeitos. Essa propriedade faz com que eles estejam sempre se renovando a cada circunstância de uso da língua, pois toda interação contribui para a permanência dos gêneros. No entanto, se os gêneros estão sempre unidos aos contextos sociais, são "relativamente estáveis", pois as transformações que ocorrem em sociedade viabilizam novas formas de interação e, assim, novos gêneros. Por exemplo, o surgimento da internet e dos celulares impulsionou outros modos de atividades comunicativas, como vídeo conferência, fórum eletrônico, scraps, torpedos, entre outros.

Mesmo reconhecendo a diversidade e a maleabilidade dos gêneros, resultantes das diferenças ideológicas dos diversos contextos sociais, Bakhtin defende que só o estudo dos tipos relativamente estáveis de enunciados pode favorecer a investigação do fenômeno linguístico em sua totalidade e complexidade.

Por essa razão, desde o final da década de 1990, diversos pesquisadores e educadores, motivados pela publicação dos Parâmetros Curriculares Nacionais de Lingua Portuguesa (Brasil, 1998), vêm defendendo os gêneros discursivos como objeto de ensino de língua portuguesa na escola, destacando a necessidade de se considerar as particularidades dos gêneros nas atividades de leitura e produção de textos.

Aqueles que adotam a perspectiva dos gêneros do discurso partirão sempre de uma análise em detalhe dos aspectos sócio-históricos da situação enunciativa, privilegiando, sobretudo, a vontade enunciati$v a$ do locutor - isto é, sua finalidade, mas também e principalmente sua apreciação valorativa sobre seu(s) interlocutor(es) e tema(s) discursivos - e, a partir desta análise, buscarão as marcas linguísticas (formas do texto/enunciado e da língua - composição e estilo) que refletem, no enunciado/texto, esses aspectos da situação. (RoJo, 2005, p. 199)

Assim, ao se tomar os gêneros discursivos para as situações de ensino da língua, parte-se das condições sociais concretas em que os gêneros estão inseridos, isto é, investiga-se quem fala (ou escreve), para quem fala, o que fala, para que fala, quando e onde fala (em que situação social, cultural, espacial e temporal). 


\subsubsection{Particularidades do gênero discursivo entrevista}

A entrevista faz parte de diversas práticas sociais como, por exemplo, da prática social da consulta médica; da seleção de candidatos a empregos, a vagas de concurso público e de pós-graduação; da coleta de dados de pesquisas científicas; da produção de reportagens e telejornais, dentre outras. Tomando-se a distinção proposta por Bakhtin (2003), entre gêneros primários e secundários, Farias (1999) afirma que "o gênero entrevista estaria mais próximo dos secundários, uma vez que nele a individualidade de quem fala é limitada pela formalidade, padronização e estereótipo impostos pelo gênero" (p. 21).

Interessa-nos, aqui, a entrevista como prática de linguagem oral que passa por uma adaptação escrita e que é difundida em meios jornalísticos escritos, como o jornal, a revista e os sites de internet; sendo assim, ela é um gênero oral que passou por uma adaptação escrita. Por meio dela, há o objetivo de se coletar informações, opiniões, experiências vivenciais e profissionais de alguma pessoa, em geral, de destaque, bem como formar opinião de leitores.

Para que possa trabalhar apropriadamente esse gênero com os alunos, o professor precisa conhecer, além das características citadas, as referentes ao conteúdo temático, ao estilo e à construção composicional, as quais estão indissoluvelmente ligadas ao todo da entrevista e refletem as especificidades do campo de atividade, neste caso, do campo jornalístico (BAKHTIN, 2003).

Entendemos que o conteúdo temático está unido aos objetivos, tipos de informação e público-alvo de uma revista. Nesse sentido, Hoffnagel (2003) sugere três modalidades gerais: a) aquelas que entrevistam algum especialista, muitas vezes pouco conhecido, em algum assunto com a finalidade de explicar um fenômeno; b) as que entrevistam uma autoridade, em geral conhecida pelo público, para obter sua opinião a respeito de um evento em destaque nas notícias; c) as que entrevistam pessoas públicas (políticos, artistas etc.) para promover o entrevistado, ou grupo que ele representa, ou de fazer com que o público conheça melhor a pessoa entrevistada. Sendo assim, as entrevistas versam sobre a pessoa do entrevistado ou sobre um assunto de conhecimento dele.

Quanto à estrutura composicional, observam-se os seguintes elementos: o nome da seção e o nome do entrevistado; o título; o nome 
do jornalista; a introdução, que contextualiza o entrevistado e enfatiza o seu papel social, suas realizações e o assunto/tema sobre o qual ele se pronuncia; e a sequência de perguntas e respostas introduzidas pelo nome da revista e pelo nome do entrevistado. Nessa sequência, pode aparecer a intercalação de "olhos" e fotografia(s) do entrevistado. Em algumas revistas, a entrevista é apresentada em colunas e destacada em folha de cor diferente de branco. (Silva; Rodrigues, 2009).

Os aspectos referentes ao estilo estão relacionados com os objetivos da revista, com o tipo de informação pretendida, com o perfil do público-leitor e com o perfil do entrevistado; portanto, mostram-se bastante diversificados. Por exemplo, se a intenção é promover a pessoa do entrevistado, que é uma celebridade no país, podem-se verificar, por parte do entrevistador, perguntas em tons mais elogiosos. Também podem ser encontradas, dependendo do viés político da revista, perguntas mais ou menos "politicamente corretas" e que denotam a linha seguida pelo veículo de comunicação, afinal, nenhum veículo é politicamente neutro.

Na seção 2, a seguir, daremos ênfase ao livro didático selecionado para a análise.

\section{O LIVRO DIDÁTICO EM ANÁLISE}

Conforme já salientado, tomou-se como objeto de análise o livro Português: uma proposta para o letramento $-8^{\circ}$ ano do Ensino Fundamental, da autora Magda Soares (2002), que faz parte do Guia de Livros Didáticos - PNLD/2011 (BRAsIL, 2010), último guia dos anos finais do Ensino Fundamental. Tomamos como base esse livro porque é usado, nas aulas de Língua Portuguesa, em muitas escolas da região de abrangência da Unicentro.

Os livros da coleção selecionada pelo Guia do PNLD/2011 estão organizados em unidades temáticas: cada unidade apresenta um conjunto de textos de diferentes gêneros sobre um mesmo tema, abordado a partir de pontos de vista diferenciados. As atividades didáticas estão distribuídas em seções de: a) leitura (preparação para a leitura, leitura oral, leitura silenciosa, interpretação oral, interpretação escrita, sugestões de leitura); b) produção de texto; c) linguagem oral; d) língua oral - língua escrita; e) vocabulário e f) reflexões sobre a língua. 
O livro de Soares (2002) encontra-se dividido em quatro unidades. A unidade três, denominada "Diferentes, mas iguais", discute a questão da pluralidade étnica e cultural, da discriminação e do preconceito. Para favorecer essa discussão, a unidade apresenta os gêneros poema, reportagem, entrevista e cartaz. As atividades de leitura do gênero entrevista são o objeto de nossas análises.

As orientações teóricas e metodológicas ao professor são apresentadas, no manual do professor, página a página na margem do meio do livro - segundo a própria autora, "a fim de que a interação autor-leitor ocorra no momento mesmo em que as atividades de ensino e de aprendizagem são propostas" (p. 3) - e ao final, num encarte denominado "Sobre esta coleção". A autora destaca como fundamentos teóricos da coleção: o letramento como fundamento e finalidade do ensino de português; a concepção de língua como discurso; o texto como unidade de ensino e os gêneros como modos de dizer. De acordo com Soares (2002),

tornar-se alfabetizado significa adquirir uma tecnologia, a de codificar em língua escrita (escrever) e de decodificar a língua escrita (ler); não basta, porém adquirir essa tecnologia, é preciso apropriar-se da escrita [...]. Letramento é o estado ou condição de quem não só sabe ler e escrever, MAS exerce as práticas sociais de leitura e de escrita que circulam na sociedade em que vive, conjugando-as com as práticas sociais de interação oral. (p. 5; grifos da autora)

Além disso, a autora ainda afirma:

Considera-se aqui a língua como processo de interação (inter-ação) entre sujeitos, processo em que os interlocutores vão construindo sentidos e significados ao longo de suas trocas linguísticas, orais ou escritas, sentidos e significados que se constituem segundo as relações que cada um mantém com a língua, com o tema sobre o qual fala ou escreve, ouve ou lê, segundo seus conhecimentos prévios, atitudes e "pré-conceitos", segundo ainda as relações que os interlocutores mantêm entre si, segundo a situação específica em que interagem, segundo o contexto social em que ocorre a interlocução. É à atividade linguística assim entendida que se chama discurso, atividade que se materializa, pois, em práticas discursivas constituídas segundo as condições de produção do discurso. (p. 5-6; grifos da autora) 
A interação pela linguagem materializa-se em textos, orais ou escritos. [...] Como muito numerosas são as finalidades com que são produzidos os textos no contexto social, muito numerosos são os gêneros. Nesta coleção, utilizam-se, como unidade básica do ensino, textos de muitos e diversos gêneros, priorizando-se, porém, aqueles gêneros que são mais frequentes ou mais necessários nas práticas sociais de leitura. (p. 8)

Assumindo essas concepções, a autora pretende propiciar condições para que o aluno aprenda não só a decodificar a língua escrita, mas faça uso das práticas sociais de leitura. Para isso, defende que a língua seja vista não somente como meio de transmissão de mensagens, mas como um processo interativo. Nesse sentido, as práticas discursivas materializadas em diferentes gêneros e, portanto, constituídas conforme determinados condicionamentos sociais (quem fala, para quem fala, para que fala, em que momento fala etc.) devem governar toda a ação pedagógica na sala de aula, rompendo-se com a indesejada fragmentação e o artificialismo de se trabalhar a lingua(gem) como mero conteúdo escolar. Dessa forma, há uma prática viva da língua.

Os fundamentos teóricos da coleção corroboram os pressupostos atuais da Linguística e da Linguística Aplicada e trazem contribuições ao pensar e fazer pedagógico do professor. Entretanto, seria importante que houvesse, no referencial teórico, um aprofundamento acerca das noções de língua como discurso e de gêneros discursivos para melhor subsidiar a prática do professor e, assim, as aulas de Língua Portuguesa poderiam propiciar ao aluno de forma mais efetiva a reflexão e o consequente domínio dos usos sociais da língua.

\subsection{Atividades de leitura do gênero discursivo entrevista}

O texto "Papo-cabeça pra pensar" é um dos que compõem a Unidade 3 do livro didático em análise. Trata-se de uma entrevista, em que não aparece o nome do jornalista, feita ao cantor e compositor Martinho da Vila, publicada na revista Almanaque Brasil de Cultura Popular, no mês de novembro de 1999, com o objetivo de discutir o tema preconceito racial, haja vista o subtítulo dado à entrevista: "Sem preconceito nenhum sou preto". 
Retomando as modalidades gerais de Hoffnagel (2003), citadas anteriormente, temos aqui um bom exemplo da modalidade "b", em virtude de a entrevista ter sido feita com uma autoridade, um cantor negro conhecido pelo público, para obter sua opinião a respeito de um evento em destaque nas notícias: o preconceito racial.

As primeiras propostas para o estudo do gênero entrevista, que se encontram inseridas na seção "Preparação para a leitura", preocupam-se com a investigação acerca do âmbito em que se insere o texto:

Preparação para a leitura

Vocês vão ler uma matéria que foi publicada nesta revista:

(segue no livro a reprodução reduzida da capa da revista Almanaque Brasil de Cultura Popular)

Identifiquem em que mês e ano foi publicado esse número da revista. Observem, na parte inferior da capa, o destaque para um certo dia do mês em que foi publicado esse número: que dia é e o que se comemora nesse dia?

$[\ldots]$

Vejam a cópia reduzida das páginas que apresentam o papo-cabeça com Martinho da Vila, grande nome da música popular brasileira:

$[\ldots]$

Prevejam: qual será o tema desse papo-cabeça?

(Soares, p. 152)

Essas atividades possibilitam que o aluno recupere algumas das condições de produção da entrevista: o momento histórico em que a entrevista foi publicada (quando foi publicada); o acontecimento social que a motivou; e o lugar social do texto (onde a entrevista circula). Isso faz com que o aluno perceba, portanto, que a matéria a ser lida foi publicada na revista Almanaque Brasil de Cultura Popular, com periodicidade mensal, no mês de novembro de 1999, data em que se comemora o Dia Nacional da Consciência Negra (dia 20 de novembro) e, acima de tudo, permite que se discuta que a entrevista é um gênero oral que passou por uma adaptação escrita. Conhecer o contexto da interação, o "horizonte espacial e temporal" (Rodrigues, 2005), proporciona condições para que o aluno observe o texto não apenas em suas peculiaridades formais, mas em funcionamento, dentro de uma determinada esfera social de interação. 
Destaque-se, também, como um ponto positivo do manual didático, o fato de apresentar a cópia reduzida, tanto da capa da revista como da entrevista; assim, o leitor visualiza a entrevista conforme foi publicada originalmente, o que lhe permite, em situações reais de comunicação, identificar o gênero discursivo, bem como adquirir elementos importantes para a construção de sentidos na leitura do gênero. Entendemos que extraindo a entrevista de seu suporte original e levando-a ao livro didático, dá-se oportunidade para que o aluno tenha acesso a textos que circulam na sociedade e que se mostram mais próximos de sua realidade.

Acreditamos que outras informações poderiam ser exploradas para favorecer o exercício de criticidade dos alunos, pois entendemos que o professor não deve ser um mero seguidor do livro didático, mas deve assumir, perante o material, uma posição ativa e criativa, avaliando criticamente as propostas oferecidas, construindo outras que melhor atendam às especificidades do contexto em que trabalha. No caso da unidade selecionada, por exemplo, o professor poderia analisar com os alunos o tipo de público que tem acesso a essa revista. Como no canto esquerdo superior da capa há a inscrição "Exemplar de quem viaja TAM", essa informação possibilita levantar o lugar social em que a revista circula, bem como o tipo de leitor pretendido e os possíveis objetivos do leitor ao ler a revista.

Recuperar o interlocutor pretendido é fundamental no estudo de todo e qualquer gênero, pois o interlocutor condiciona a interação verbal, ele funciona como uma baliza que orienta a ação do locutor, além de orientar a escolha da linguagem e a carga informativa do processo de interlocução.

Outra questão que, para nós, possibilitaria o exercício da crítica está relacionada com a última pergunta: "Prevejam: qual será o tema desse papo-cabeça?". Além de levantar o tema ${ }^{3}$ da entrevista, ou seja, o que é dizível por meio do gênero (BAKHTIN, 2003) - o qual pode ser facilmente recuperado quando o aluno observar a cópia reduzida - torna-se fundamental questionar "Por que esse tema mereceu ser veiculado na revista?"; "Com que finalidade esse tema foi escolhido?"; "Por que o entrevistado escolhido foi Martinho da Vila?"

Vale ressaltar que hoje o tema da entrevista é amplamente discutido no cenário nacional e que Martinho da Vila é um cantor famoso, 
negro, o que demonstra que nem todas as pessoas da cor dele são mal sucedidas - questões essas que também poderiam ser propostas e discutidas no livro didático. Além disso, o conceito de "raça" poderia ser discutido em sala de aula pelo professor, trazendo à tona, por exemplo, várias atrocidades históricas que já foram cometidas por se levar às últimas consequências a classificação das pessoas segundo esse conceito. ${ }^{4}$

A próxima seção - "Leitura silenciosa" - reproduz partes da entrevista realizada com Martinho da Vila e, na sequência, a seção "Língua oral - língua escrita" registra cinco atividades referentes ao texto. Inicialmente, o livro procura levar ao conhecimento do aluno algumas características constitutivas do gênero entrevista:

1. Releiam a primeira pergunta da entrevista:

"Como você vê as conquistas?"

a. Conquistas de quê? Por quem?

b. Por que o entrevistador não precisou dizer nem ao entrevistado nem ao leitor a que conquistas se referia?

2. Um de vocês vai ler em voz alta a resposta de Martinho da Vila à primeira pergunta. Em seguida, identifiquem o que ficou implícito nas expressões abaixo, depois expliquem por que o entrevistado pôde deixar estas informações implícitas: [...]

(SOARES, 2002, p. 155)

Constata-se que as particularidades do gênero não estão claramente expostas na unidade, mas podem ser construídas pelo aluno por meio das perguntas de interpretação de texto. As perguntas propostas ali levam o aluno a descobrir que, no gênero entrevista, muitas informações não são explicitadas, elas ficam subentendidas na situação, ou seja, todo texto tem seus implícitos em que nem tudo é dito. Logo, o conhecimento partilhado precisa atuar para que se façam as inferências necessárias.

Construída pelo entrevistador e entrevistado, esse gênero apresenta características interativas, já que se mostra em forma de diálogo, pergunta/resposta, a fim de divulgar fatos e ideias de um dos participantes, na maioria das vezes de pessoas públicas, com o objetivo de expor melhor sua identidade pública e pessoal. Embora o objetivo seja divulgar as ideias do entrevistado, não há como negar que o entrevistador, que é quem direciona a entrevista, limitando as possibilidades ar- 
gumentativas do entrevistado, também deixa opiniões nas perguntas ou nos comentários que realiza - que estão sempre em consonância com o veículo em que a entrevista é publicada - tal como acontece nos trechos seguintes, e que poderiam ser explorados nas atividades de leitura:

Entrevistador: O povo negro tem consciência de sua história? Se não tem, por que não tem $[\ldots]$

Entrevistador: A surrada questão que se discute é por que negro que sobe na escala social casa com branca.

Assim, a escolha de determinadas perguntas e o modo como elas são realizadas não se enquadram em um campo "neutro", mas evidenciam certas opiniões do entrevistador (e da revista).

As próximas questões selecionadas do livro analisado visam ao trabalho com as características referentes ao estilo do gênero entrevista:

3. Tanto o entrevistador quanto o entrevistado usam a primeira pessoa do plural (nós, nos, nosso), mas nem sempre estão se referindo ao mesmo grupo de pessoas: a situação em que estão conversando e o assunto sobre o qual falam é que esclarecem a quem estão se referindo em cada frase.

Identifiquem a quem se refere a primeira pessoa do plural em cada frase abaixo.

a. Na segunda pergunta, o entrevistador diz:

"Mas nós temos a peculiaridade da mestiçagem..."

Nós se refere a que grupo de pessoas?

$[\ldots]$

4. Quando o entrevistado usa você, não se refere ao entrevistador, mas a uma pessoa não especificada, "alguém".

Expliquem o "você" nas seguintes frases do entrevistado:

Aqui tratam você muito bem..."

Você não é o entrevistador... você é alguém com que características? (SOARES, 2002, p. 156-157)

Esses exercícios trabalham com os pronomes inseridos no contexto da interação. A autora do livro demonstra que, para conhecer um gênero, o leitor precisa apropriar-se das suas particularidades linguísticas; portanto, não há sentido em abordar as questões de gramática em seção à parte, desvinculadas das atividades de leitura. Seria interessante que se questionasse a relação entre a escolha de determinados elemen- 
tos linguísticos e as condições de produção como, por exemplo: "Por que o entrevistador insere-se na entrevista?"; "Há alguma relação dessa marca (o uso do "nós") com o interlocutor pretendido e com o objetivo da entrevista?"; "Por que o entrevistado usou o pronome você e não o pronome $t u$ ?"; "Você conhece algum falante que use o pronome $t u$ ? Em caso afirmativo, de que região ele é?"; e "Em que regiões do Brasil ainda se usa o pronome $t u$ ?"

Na nossa opinião, são muito boas e válidas as questões que exploram o uso das aspas:

2. Na parte inicial do texto, que precede e anuncia a entrevista, há duas frases entre aspas.

a. Qual é a razão do uso das aspas nessas frases?

b. Quem fala cada uma dessas frases?

c. Que relação cada uma delas tem com o conteúdo da entrevista? (SOARES, 2002, p. 158)

A primeira e a segunda pergunta permitem que o aluno perceba que as aspas evidenciam, nesse contexto, a citação de frases de outras pessoas, não do jornalista. Já a terceira mostra que a escolha dessas frases não é aleatória, mas sintetiza a opinião do entrevistado, persuadindo o leitor a uma postura diante do fato discutido, mesmo antes de ler a matéria.

Há preocupação, também, em proporcionar situações para que o leitor posicione-se criticamente acerca da qualidade das informações expostas na matéria:

5. O entrevistador pergunta a opinião de Martinho da Vila sobre o sistema de cotas (terceira pergunta): o cantor se declara favorável. $[\ldots]$

b. Você concorda com esse argumento?

$[\ldots]$

9. c. Você concorda que o problema para os negros no Brasil, atualmente, é a dificuldade de acesso e não o preconceito doentio?

10. O entrevistado manifesta algumas vezes, na entrevista, sua opinião sobre a situação dos negros nos Estados Unidos. [...]

b. Você acha que o entrevistado tem razão? Justifique sua opinião. 
11. No parágrafo que introduz a entrevista é mencionado o otimismo contagiante de Martinho da Vila.[...]

b. O otimismo de Martinho da Vila contagiou você? Você concorda com o otimismo dele?

(SOARES, 2002, p. 158-159)

Essas perguntas buscam a reação do leitor, ao incitá-lo a emitir um julgamento de valor acerca do conteúdo veiculado na entrevista. A leitura, nessa perspectiva, não se revela como um ato monológico, de mera localização de informações, mas sugere uma concepção de ler como réplica (Menegassi, 2010; Rojo, 2004), como atitude responsiva. Dessa forma, alça-se o leitor à condição de um sujeito ativo e crítico que toma a palavra do outro para avaliá-la e questioná-la.

\section{CONSIDERAÇÕES FINAIS}

As atividades da unidade analisada são consideradas boas porque permitem que o aluno tenha acesso ao gênero discursivo entrevista e podem suscitar valiosas reflexões em sala de aula. Consideram-se como pontos positivos os seguintes aspectos das atividades: há a preocupação em se trabalhar algumas condições de produção da entrevista (onde e em que momento foi publicada); apresenta-se a cópia reduzida, tanto da capa como da entrevista, o que leva o aluno a perceber as peculiaridades do suporte típico do gênero; há questões que, de acordo com o enfoque bakhtiniano, despertam no aluno a réplica ativa; os elementos linguísticos são trabalhados no contexto da interação; permite-se que o aluno construa as características do gênero entrevista por meio das perguntas de compreensão.

No entanto, outros questionamentos podem ser feitos pelo professor, em sala de aula, como meio de complementar as atividades propostas no livro, para que os alunos se tornem leitores mais proficientes desse tipo de gênero. Vale ressaltar a relevância de se trabalhar a língua como prática social que vai muito além do mero conteúdo escolar como, por exemplo, trabalhar as noções de interlocutor e autoria (entrevistador/entrevistado); a finalidade social da entrevista; os vínculos entre a seleção das marcas linguísticas; os usos dessas marcas pelos falantes e as condições de produção. 
THE TEXTBOOK AND THE READING ACTIVITIES ON INTERVIEW GENRE

\section{AbSTRACT}

Based on the Bakhtinian assumptions, this paper analyzes the reading activities on interview genre presented in the textbook Português: uma proposta para letramento (SOARES, 2002). The results show that the proposals of the book may raise important considerations in the Portuguese Language classes as there are issues that awaken the student to active replica. However, there are other issues that can be brought into the classroom by the teacher, for example, the notions of speaker and author; the social purpose of the interview, the links between the selection of linguistic marks and language conditions of production.

KEY WORDS: reading activities, interview genre, textbook.

\section{NotAS}

1 Agradecemos aos pareceristas que avaliaram este texto pelas sugestões apresentadas.

2 Neste trabalho, estamos adotando a teoria dos gêneros discursivos que privilegia a investigação das situações de produção dos textos em seus aspectos sociais e ideológicos. Há outra vertente, denominada gêneros textuais, que, embora se fundamente na teoria de Bakhtin, privilegia a descrição da materialidade linguística (cf. Rojo, 2005).

3 Em relação à noção de tema na obra de Bakhtin, vale consultar o texto de Grillo (2006).

4 A respeito desse assunto, o livro didático poderia trazer sugestões de leitura para que o professor pudesse ter um melhor aprofundamento sobre o tema do pensamento racial, como o livro de Magnoli (2009), por exemplo. Essa indicação não é feita pelo livro analisado.

\section{REFERÊNCIAS}

Brasil, Secretaria de Educação Fundamental. Parâmetros Curriculares Nacionais: terceiro e quarto ciclos do ensino fundamental: língua portuguesa. Brasília: MEC/SEF, 1998.

Brasil, Ministério da Educação. Guia de Livros Didáticos - PNLD/2011: Língua Portuguesa. Ministério da Educação, Brasília: MEC, 2010. 
Bakhtin, M. M. Estética da criação verbal. Tradução do russo por Paulo Bezerra. 4. ed. São Paulo: Martins Fontes, 2003.

Bakhtin, M. M.; Volochinov, V. N. Marxismo e filosofia da linguagem: problemas fundamentais do método sociológico na ciência da linguagem. Tradução do francês por Michel Lahud e Yara Frateschi Vieira. 9. ed. São Paulo: Hucitec, 1999.

FARIAS, A. M. Entrevista escolar: uma possibilidade de construção de metaconhecimento? 110p. Dissertação (Mestrado em Linguística Aplicada ao Ensino de Línguas) - Pontifícia Universidade de São Paulo, São Paulo, 1999.

Grillo, S. V. C. A noção de "tema do gênero" na obra do Círculo de Bakhtin. Estudos Linguísticos, São Paulo, v. 1, p. 1825-1834, 2006. Disponível em: $<$ http://www.fflch.usp.br/dlcv/lport/pdf/sheila_nocao_tema.pdf $>$. Acesso em: 9 set. 2013.

Hoffnagel, J. C. Entrevista: uma conversa controlada. In: Dionisio, A. P.; Machado, A. N.; Bezerra, M. A. Gêneros textuais e ensino. 2. ed. Rio de Janeiro: Lucerna, 2003. p. 180-193.

Magnoli, D. Uma gota de sangue: história do pensamento racial. São Paulo: Contexto, 2009.

Menegassi, R. J. O leitor e o processo de leitura. In: Greco, E. A.; Guimarães, T. B. (Orgs.). Leitura: aspectos teóricos e práticos. Maringá: Eduem, 2010. p. 35-59.

Rodrigues, R. H. Os gêneros do discurso na perspectiva dialógica da linguagem: a abordagem de Bakhtin. In: Meurer, J. L.; Bonini, A.; MottARотн, D. (Orgs.). Gêneros: teorias, métodos, debates. São Paulo: Parábola, 2005.

Rojo, R. Letramento e capacidades de leitura para a cidadania. São Paulo: SEE: CENP, 2004. Disponível em: <http://suzireis.bravehost.com/ posgraduacao/artigos/roxane_rojo.pdf $>$. Acesso em: 20 nov. 2010.

Rojo, R. Gêneros do discurso e gêneros textuais: questões teóricas e aplicadas. In: Meurer, J. L.; Bonini, A.; Motta-Roth, D. (Orgs.). Gêneros: teorias, métodos, debates. São Paulo: Parábola, 2005.

Silva, N. R. da; Rodrigues, R. H. O papel da inter-relação do verbo-visual no gênero entrevista pingue-pongue. Revista Anpoll, v. 2, n. 27, p. 159-186, 2009.

Soares, M. Português: uma proposta para o letramento - livro 7. São Paulo: Moderna, 2002. 